\title{
Adverse welfare shocks and pro-environmental behaviour: Evidence from the global economic crisis
}

(accepted for publication in the Review of Income and Wealth)

\section{Artjoms Ivlevs ${ }^{1}$}

Bristol Business School (UWE Bristol) and IZA (Bonn)

\begin{abstract}
This paper examines the effects of the 2008-09 global economic crisis on people's proenvironmental behaviour and willingness to pay for climate change mitigation. We hypothesise that the crisis has affected pro-environmental behaviours through tightening of budget constraints and relaxation of time constraints. Using data from a large representative survey (Life in Transition II), conducted in 35 European and Central Asian countries in 2010, we find that people adversely affected by the crisis are more likely to act in an environmentally-friendly way, but less likely to be willing to pay for climate change mitigation. Our findings confirm the importance of time and budget constraints for undertaking pro-environmental action, and highlight a potentially positive role of adverse, external welfare shocks in shaping pro-environmental behaviour.
\end{abstract}

Keywords: global economic crisis, adverse welfare shocks, pro-environmental behaviour, willingness to pay for climate change mitigation, transition economies.

JEL: G01; P28; Q53; Q54.

\footnotetext{
${ }^{1}$ Department of Accounting, Economics and Finance, Bristol Business School, University of the West of England, Bristol, BS16 1QY, UK. Tel: +44 11732 83713, E-mail: a.ivlevs@uwe.ac.uk.
} 


\section{INTRODUCTION}

With climate change becoming one of the most pressing issues of our times, there has been increasing interest, among both academics and policymakers, in what determines people's proenvironmental behaviour. One question that has received much attention in this area has been whether greater income makes people's actions more pro-environmental. As income levels have been increasing and poverty levels falling in many parts of the world, it is indeed important to understand how growing affluence affects pro-environmental behaviour. However, the path to long-term economic prosperity is often accompanied by important fluctuations in the short term, exemplified by the devastating effects of the recent global economic crisis on the lives of millions of people across the world. It is, therefore, equally important to understand how proenvironmental behaviour is affected by adverse welfare shocks. To date, this question has received little attention in the literature, and this paper fills this knowledge gap by studying the individual-level effects of a particular macroeconomic shock, the 2008-09 economic crisis, on people's pro-environmental actions.

We hypothesise that the crisis may have had a positive effect on people's pro-environmental behaviour because it tightened budgets constraints (which, for example, would force people to save water and electricity, and limit travelling by car) and/or relaxed time constraints (which, for example, would provide the necessary time for recycling household waste). At the same time, it is likely that people adversely affected by crisis become less willing to allocate a part their budget for environmental causes. To test these hypotheses, we use data from a large representative survey (Life in Transition-2), conducted by the World Bank and the European Bank of Reconstruction and Development in 35 European and Central Asian countries in 2010. The survey contains 
extensive information on respondents' pro-environmental behaviours, as well as the extent and ways in which households were affected by the global economic crisis, allowing for a nuanced analysis of the relationship between adverse welfare shocks and pro-environmental action.

Our results suggest that people adversely affected by the crisis are indeed more likely to undertake environmentally-friendly action and, at the same time, less willing to pay for climate change mitigation. Most types of crisis effects (e.g., job loss, salary reduction, reduced migrant remittances) are positively associated with pro-environmental action, and most types of proenvironmental action (e.g., reduced use of transport, reduced water and energy consumption, waste recycling) are positively associated with being adversely affected by the crisis. The positive association between the crisis and pro-environmental action is observed in low-, middle- and high-income countries, as well as across various socio-demographic groups. The negative association with the willingness to pay for climate change mitigation is driven by relatively poor and relatively rich countries, as well as people with lower levels of education. Taken together, these findings confirm the role of the crisis-induced tightened budget and relaxed time constraints for undertaking environmentally-friendly action and allocating money for environmentallyfriendly causes.

This study contributes to the literature on the individual/household-level determinants of proenvironmental behaviour. One strand in this literature has analysed pro-environmental behaviour in the consumption-leisure choice framework and emphasized the role of financial and time constraints in shaping pro-environmental action (Ando and Gosselin, 2005; Halvorsen, 2008; Jakus et al., 1996; Matsumoto, 2014). A weakness of the related empirical work is that the choices 
related to income, working hours, leisure and undertaking pro-environmental action are likely to be jointly determined, making it difficult to disentangle causal effects. From this perspective, our study makes a contribution by exploiting the crisis-induced changes in financial and time constraints; such changes come close to a natural experiment, allowing to mitigate possible endogeneity issues.

More broadly, our study also adds to the larger literature on the effects of economic development on environmental concerns, attitudes and behaviours. Most of the contributions have focused on the role of income growth, both at the country and individual level (Çarkoğlu and Kentmen-Çin, 2015; Diekman and Franzen, 1999; Dunlap and Mertig, 1995; Dunlap and Mertig, 1997;

Fairbrother, 2013; Franzen and Mayer, 2010; Franzen and Vogl, 2013; Inglehart, 1995; Israel and Levinson, 2004; Jacobsen and Hanley, 2009), and little attention has been paid to the role of adverse welfare shocks. Some evidence is provided by Scruggs and Benegal (2012), who show that higher unemployment rates (a country-level variable), which are generally attributed to economic downturns, are associated with lower environmental concern in the US and Europe. We advance this line of research by 1) using direct, household-level measures of crisis impact, 2) choosing pro-environmental behaviour and willingness to pay for climate change mitigation as outcome variables, and 3) considering a range of countries at different stages of economic development.

The paper is organised as follows. The next section outlines channels through which economic crises may affect pro-environmental behaviours, and formulates hypotheses to be tested in the 
empirical analysis. Section three presents data, variables and estimation strategy. Section four describes the results, followed by a discussion and conclusion in Section five.

\section{CRISIS AND PRO-ENVIRONMENTAL BEHAVIOUR: CONCEPTUAL CHANNELS, RELATED LITERATURE, AND HYPOTHESES TO BE TESTED}

One could conceive several channels through which crisis-related welfare shocks may affect proenvironmental behaviours. A positive change could occur where, in order to reduce expenses, people affected by crisis start saving water/energy or use public transport/walk instead of taking a car. Such pro-environmental actions are driven by a sudden tightening of financial constraints, and the argument is consistent with recent literature showing that people with lower incomes are more likely to adopt environmentally-friendly behaviours. Longhi (2013) obtains such evidence for the UK and explains it with the conjecture that people with lower incomes cannot afford the cost of more damaging environmental behaviour: for example, poor people use public transport and save energy because they cannot afford to buy a car or to pay high energy bills. Bruderer Enzler and Diekmann (2015) corroborate these results, showing that people with higher incomes produce more greenhouse gas emissions, especially in the life domains related to transport and housing.

Another positive channel is through the relaxation of time constraints. For example, losing a job or having working hours reduced allows more time to be allocated for recycling, walking rather than taking a car, or shopping for environmentally friendly products - something a person affected by crisis may have always wanted but never managed to do due to the lack of time. This argument implies the existence of opportunity costs of undertaking pro-environmental activities (such as 
forgone income or time spent on other activities); such opportunity costs have been previously analysed in the framework of labour-consumption-leisure choice and confirmed empirically, particularly in the context of recycling activities (Ando and Gosselin, 2005; Halvorsen, 2008; Jakus et al., 1996; Matsumoto, 2014). In our case, adverse crisis effects such as job loss or reduced working hours mean lower opportunity costs of pro-environmental action, which would lead to more of such action being undertaken. ${ }^{2}$

An example of a negative effect of the crisis on pro-environmental stance may be a reduction in willingness to allocate part of the budget for environmental causes (e.g., pay for climate change mitigation), as people affected by crisis choose to allocate their scarce resources to fulfilling basic needs - buying food, paying housing expenses (bills, rents, mortgage) etc. This is consistent with this conjecture that adverse welfare shocks shift one's values closer to material security and away from post-materialist goals, which include self-fulfilment, political freedom and also concern for the environment (Inglehart, 1995; Inglehart, 1997). ${ }^{3}$

Finally, from a purely technical perspective, the effect of adverse income shocks on proenvironmental behaviour could be viewed as an opposite of the effect associated with income increases. Here, numerous cross-sectional studies have documented a positive association between different manifestations of individual and household economic well-being (such as objective and

\footnotetext{
${ }^{2}$ The relaxed time constraint and reduced opportunity costs argument echoes Burgard and Kalousova (2015) who, in their review of literature on the effects of the Great Recession on health and well-being, find that people affected by the crisis gain time for exercising, cooking healthy meals, sleeping, shopping, leisure and home production, which in turn reduces stress and improves health. Aguiar et al. (2013) also report significant increases in time spent on shopping, child care, education and health among people affected by the Great Recession in the US.

${ }^{3}$ The same logic suggests that, within any country, poorer people (affected by the crisis or not) are in general less likely to pay for climate change mitigation. Note that our empirical analysis includes a control for household wealth (which indeed indicates that people with lower levels of household wealth are less willing to pay for climate change mitigation); our main interest is thus on the effects of the short-term, crisis-induced welfare shocks.
} 
self-perceived income and wealth) on the one hand, and pro-environmental concern, beliefs and behaviours on the other (Carlsson et al., 2012; Clark et al., 2003; Dorsch, 2014; Franzen and Meyer, 2010; Jacobsen and Hanley, 2009; Roco et al., 2015). Several studies have obtained a statistically insignificant relationship (Kellstedt et al., 2008; Wang et al., 2011; Whitmarsh, 2011) or showed that income matters for some aspects of pro-environmentalism but not others (Dienes, 2015; Fairbrother, 2013; Liebe et al., 2011; Wong and Wan, 2011). Finally, as already mentioned, Longhi (2013) and Bruderer Enzler and Diekmann (2015) show that there is a negative relationship between individual income and pro-environmental behaviour. If one assumes that income increases and income decreases affect pro-environmental behaviour in opposite directions, the studies by Longhi (2013) and Bruderer Enzler and Diekmann (2015) suggest that income decreases lead to more pro-environmental actions, while the other individual-level studies suggest that income decreases lead, if anything, to less pro-environmental actions. It is important to note, however, that all of the empirical studies mentioned above rely on cross-sectional data (or, in some cases, repeated cross-sections) and do not consider how a change in income of the same individuals or households over time is related to the change in their pro-environmental stance. One should, therefore, be cautious in extrapolating the findings of these correlational studies to the present analytical framework where the primary focus is on the effects of large, sudden welfare falls.

This discussion leads us to the following hypotheses:

H1: People adversely affected by an economic crisis are more likely to adopt environmentally friendly behaviours than those not affected. 
H2: People adversely affected by an economic crisis are less likely to be willing to pay for climate change mitigation than those not affected.

\section{DATA, VARIABLES AND ESTIMATION STRATEGY}

\subsection{Data}

The empirical analysis draws on data from the 'Life in Transition-2' survey, administered by the European Bank for Reconstruction and Development and the World Bank in 2010. The survey was conducted in 29 former socialist economies of Central and Eastern Europe and Central Asia, as well as Turkey and five Western European countries (France, Germany, Italy, Sweden and the UK). The nationally representative samples consisted of 1,000 respondents per country $(1,500$ respondents in the case of countries with larger populations: Russia, Ukraine, Uzbekistan, Serbia, Poland and the UK); there were 38,864 respondents altogether.

In each country, households were selected according to a two-stage clustered stratified sampling procedure. In the first stage, the frame of primary sampling units was established using national administrative information. In the second stage, households were randomly selected within the primary sampling units, and respondents within households were then selected using a selection grid. The survey summary, including detailed information on survey design and implementation methodology, is available in the official survey report (Steves, 2011), and the dataset can be accessed from the survey website. ${ }^{4}$

\footnotetext{
${ }^{4}$ http://microdata.worldbank.org/index.php/catalog/1533/
} 
Alongside extensive information on the respondents' socio-demographic backgrounds, the survey included a number of questions on climate change (section 4 of the survey) and the ways in which respondents' households were affected by the global economic crisis (section 8). This makes the dataset well suited for an analysis of the effect of adverse welfare shocks on pro-environmental behaviour.

\subsection{Variables}

\subsubsection{Outcome variables}

In line with the research hypotheses, we created two variables to capture pro-environmental behaviour at the individual level. First, all respondents were asked, "Have you personally taken actions aimed at helping to fight climate change?" If the answer was affirmative, the respondents were asked to specify, referring to a list of ten options, which actions they had taken (multiple answers were possible). These actions, along with the percentage of respondents who had undertaken them, are reproduced in Table 1. Recycling and reducing energy consumption are the most common actions (indicated by $17 \%$ of respondents), followed by reducing water consumption (15\%), reducing consumption of disposable items (12\%), and choosing environmentally friendly means of transportation (10\%). Overall, $28 \%$ of respondents indicated they had undertaken at least one pro-environmental action. We created separate dummy variables to capture each of the ten actions. In addition, we created a dummy variable for undertaking at least one pro-environmental action. ${ }^{5}$

\footnotetext{
${ }^{5}$ In a further robustness check, we constructed an index of pro-environmental behaviour, based on principal components, which captures the common variation among the ten pro-environmental dummies (we retained only the first principal component with the eigenvalue of 4.10; the eigenvalues of the subsequent components were lower than 1). The results, available on request, are consistent with the variable capturing at least one pro-environmental action.
} 


\section{Table 1. Types of pro-environmental actions and the percentage of respondents who have undertaken them}

Which of the following actions aimed at fighting climate change have you personally taken?

$\%$ of respondents

1. Purchased a car that consumes less fuel or is more environmentally friendly

2. Reduced the use of my car, for example by car sharing or using my car more efficiently

3. Chosen an environmentally friendly means of transportation (by foot, bicycle, public transport)

4. Reduced energy consumption at home

5. Reduced consumption of water at home

15.2

6. Where possible, avoided taking short-haul flights

2.6

7. Started separating most of my waste for recycling

17.2

12.3

8.1

9. Bought seasonal and local products to avoid products that come from far away, and thus contribute to $\mathrm{CO}^{2}$ emissions

10. Installed equipment in my own home that generates renewable energy

Has taken at least one pro-environmental action

Source: Life in Transition-2 survey.

Second, the respondents were asked, "Would you be willing to give part of your income or pay

more taxes, if you were sure that the extra money was used to combat climate change?" Overall, $31 \%$ of the respondents gave an affirmative answer. ${ }^{6}$ We created a dummy variable equal to 1 if the respondent is willing to sacrifice part of their income to combat climate change and 0 otherwise.

\subsubsection{Main regressors(s)}

One of the objectives of the "Life in Transition-2" survey was to ascertain the extent and particular ways in which households were affected by the global economic crisis. First, respondents were asked, "How much, if at all, has the economic crisis affected your household in

\footnotetext{
${ }^{6}$ Note that answers to this question are potentially subject to social desirability bias.
} 
the last two years?", with possible answers "not at all”, "just a little", "a fair amount" and "a great deal" (the respective distribution of answers is $27,23,27$ and $17 \%$ ). ${ }^{7}$ We created four dummy variables to capture each of the answers. In a follow-up question, all respondents who said they were affected by crisis "just a little", "a fair amount" and "a great deal” were asked about specific ways in which the crisis affected them. A listof seven adverse effects was offered, and respondents were asked to choose any item that applied, and furthermore to specify the most important one. The distribution of the most important effects is shown in Table 2. Wage reduction was by far the most common effect of the crisis on households (19\% of all respondents indicated it was the most important effect), followed by the reduced flow of migrant remittances (8\%) and the job loss of either the head of the household or another household member (7-8\%). A set of seven dummy variables was created to capture these effects.

\section{Table 2. Effects of the crisis at the household level}

\begin{tabular}{lc}
\hline $\begin{array}{l}\text { How has the economic crisis affected you (or other household members) } \\
\text { in the past two years? }\end{array}$ & $\begin{array}{c}\text { Choose the most } \\
\text { important (\% of } \\
\text { total sample) }\end{array}$ \\
\hline 1. Head of household lost job & 7.8 \\
2. Other household member lost job & 7.1 \\
3. Family business closed & 1.6 \\
4. Working hours reduced & 3.4 \\
5. Wages delayed or suspended & 5.4 \\
6. Wages reduced & 19.0 \\
7. Reduced flow of remittances & 7.9 \\
\hline
\end{tabular}

Source: Life in Transition-2 survey.

\subsubsection{Control variables}

\footnotetext{
${ }^{7}$ This distribution excludes respondents who did not give an answer to the question ( $6 \%$ of the sample). However, the non-respondents are not dropped from the analysis - all regressions include a dummy variable capturing those respondents who did not answer the crisis question (results for this variable are available in the Supplementary information document containing full econometric output). Our results also remain qualitatively unchanged if the non-respondents are dropped from the analysis.
} 
Following the empirical literature on the micro-determinants of pro-environmental behaviour (see, e.g. Longhi, 2013), all regressions include the following socio-demographic controls: ${ }^{8}$ dummy variables for gender, six age groups $(18-24,25-34,45-54,55-64,65+)$, marital status (married/living with a partner), having children in the household, three education levels (primary, secondary, tertiary), three types of geographical residence (rural, urban, metropolitan). In addition, as a proxy for household wealth we created, with principal components, an index capturing the possession of eight household assets: car, secondary residence, bank account, debit card, credit card, mobile phone, computer and internet access at home. This variable captures the longer-term underlying economic position of a household, as opposed to the crisis variables which capture short-term welfare shocks.

In addition, in all regressions we include controls for environmental concern, knowledge and beliefs, which are important determinants of pro-environmental action (see, e.g., Bennett, 2011; Carlsson et al., 2012; Dienes, 2015; Liebe et al., 2011; Longhi, 2013; Van Prooijen and Sparks, 2014; Wicker and Becken, 2013). For environmental concern, the respondents were asked, "How concerned are you about climate change? Please answer on a scale of 1 to 5 , where 1 means that you are not at all concerned and 5 means you are extremely concerned." Using this information, we created a variable concerned about climate change with values of 1 to 5 . For environmental knowledge, the respondents had to evaluate, on a scale of 1 to 4 , how well they were informed about: 1) the causes of climate change; 2) the consequences of climate change; 3) ways in which one can slow down climate change; and 4) ways in which one can adapt to climate change, where 1 indicates "not at all informed" and 4 "very well informed". We summed respondents' answers to these four questions to create an index of informedness about climate change, which ranges from

\footnotetext{
${ }^{8}$ See Appendix for the summary statistics of all variables included in the analysis.
} 
4 to 16 . For environmental beliefs, respondents were asked to what extent they agreed with the following statements: "The seriousness of climate change has been exaggerated" and "Emission of $\mathrm{CO}^{2}$ has a major impact on climate change", with five possible answers ranging from 1 (strongly disagree) to 5 (strongly agree). Reversing the answer value scale for the first statement and then adding together respondents' answers to the two statements, we obtained an index of proenvironmental beliefs, which ranges from 2 to 10 . Higher values of this variable indicate lower levels of scepticism about the seriousness of climate change and a stronger conviction that greenhouse gas emissions have a major impact on climate change.

Finally, to control for all possible country-wide effects (such as GDP per capita and environmental quality) on pro-environmental behaviour as well as on the extent of the crisis, all regressions include country-fixed effects (a dummy variable for each country). Among other things, this ensures that the estimated coefficients are driven by within-country, and not betweencountry, relationships between the variables of interest.

\subsection{Estimation strategy}

Pro-environmental behaviour of individual $i$ from country $j$ is modelled as follows:

$$
\begin{aligned}
\text { Pro-environmental action }_{i j}= & \beta_{0}+\beta_{1}(\text { affected by crisis })_{i j}+ \\
& \beta_{2}(\text { environmental concern })_{i j}+ \\
& \beta_{3}(\text { environmental knowledge })_{i j}+ \\
& \beta_{4}(\text { environmental beliefs })_{i j}+ \\
& \beta_{5}(\text { (socio-demographic controls })_{i j}+ \\
& \beta_{6}(\text { country-fixed effects })_{j}+\varepsilon_{i j}
\end{aligned}
$$


where the dependent variable is either pro-environmental action or willingness to pay to combat climate change, $\beta_{1}$ represents the parameters (parameter vectors) of interest, and $\varepsilon_{i j}$ is the idiosyncratic error term.

The models were first estimated for the full sample. Then, to get a better understanding of the relationships of interest, we looked at 1) how being affected by the crisis relates to the likelihood of undertaking specific pro-environmental actions; 2) whether different types of crisis effects (e.g., job loss and wage reduction) relate to pro-environmental behaviour in the same manner; 3) whether the relationship between the crisis and pro-environmental behaviour is the same in the low, middle and high income countries, and 4) whether the relationship between the crisis and pro-environmental behaviour is the same across different socio-demographic groups.

Given the binary nature of the dependent variables, the models were estimated binary probit. ${ }^{9}$ In all estimations we used heteroscedasticity-robust standard errors and applied within-country population weights available from the survey dataset.

\section{RESULTS}

Table 3 reports the full-sample results of the models estimating the relationship between the effects of the crisis one the one hand, and pro-environmental action and willingness to pay for climate change mitigation, on the other. Other factors being equal, people affected by the crisis are more likely to report that they have undertaken a pro-environmental action (column 1). In

\footnotetext{
${ }^{9}$ As a robustness check, the models were also estimated with logit and OLS. The results, available on request, remain qualitatively unchanged.
} 
terms of marginal effects and relative to people not affected by the crisis, those affected "just a little", "a fair amount" and "a great deal" are 2.9, 3.9 and 3.8 percentage points, respectively, more likely to have acted in an environmentally friendly way. These are non-negligible effects relative to the baseline incidence of undertaking pro-environmental action (27.5\%). Next, compared to people not affected by the crisis, those affected by it "a fair amount" and "a great deal" are 1.7 and 3.4 percentage points less likely to be willing to pay to combat climate change (column 2). Overall, the results lend support to hypotheses H1, H2: compared to those not affected by the crisis, people affected by it are more likely to act in an environmentally friendly way but less likely to be willing to sacrifice part of their income to combat climate change.

As for the coefficients of control variables, we notice close correspondence between our findings and the literature. Being concerned about climate change, being informed about climate change, and holding pro-environmental beliefs are all strong predictors of pro-environmental action and willingness to pay for climate change mitigation (for similar findings in the literature, see e.g. Akter and Bennett, 2011; Carlsson et al., 2012; Dienes, 2015; Liebe et al., 2011; Longhi, 2013; Van Prooijen and Sparks, 2014; Wicker and Becken, 2013). Among demographic characteristics, women, older people and married people are more likely to report environmentally friendly action (Franzen and Meyer, 2010; Meyer, 2015; Longhi, 2013); this said, gender, age and marital status play no role in the willing to pay for climate change mitigation model. There is a strong positive association between education and income, on the one hand, and pro-environmental action and willingness to pay for climate change mitigation, on the other, which is again consistent with the literature (Carlsson et al., 2012; Clark et al., 2003; Dorsch, 2014; Franzen and Meyer, 2010; Jacobsen and Hanley, 2009; Meyer, 2015, Roco et al., 2015). Finally, relative to people living in 
urban areas, both rural and metropolitan residents are less likely to undertake pro-environmental action and rural dwellers are somewhat less likely to be willing to pay for climate change mitigation, which corroborates some previous findings in the literature (Ambrosius and Gilderbloom, 2015).

Table 3. Effects of the crisis and pro-environmental behaviour, binary probit marginal effects

\begin{tabular}{|c|c|c|c|c|}
\hline & \multicolumn{2}{|c|}{$\begin{array}{c}\text { Undertaken least one pro- } \\
\text { environmental action }\end{array}$} & \multicolumn{2}{|c|}{$\begin{array}{c}\text { Willing to pay for climate } \\
\text { change mitigation }\end{array}$} \\
\hline \multicolumn{5}{|l|}{ Affected by crisis: } \\
\hline Not at all & Ref. & & Ref. & \\
\hline Just a little & $0.029 * * *$ & $(0.007)$ & 0.009 & $(0.008)$ \\
\hline A fair amount & $0.039 * * *$ & $(0.007)$ & $-0.017 * *$ & $(0.008)$ \\
\hline A great deal & $0.038 * * *$ & $(0.008)$ & $-0.034 * * *$ & $(0.009)$ \\
\hline Concerned about climate change & $0.052 * * *$ & $(0.002)$ & $0.060 * * *$ & $(0.003)$ \\
\hline Informed about climate change & $0.031 * * *$ & $(0.001)$ & $0.008 * * *$ & $(0.001)$ \\
\hline Pro-environmental beliefs & $0.025 * * *$ & $(0.002)$ & $0.027 * * *$ & $(0.002)$ \\
\hline Women & $0.012 * *$ & $(0.005)$ & 0.004 & $(0.005)$ \\
\hline \multicolumn{5}{|l|}{ Age group } \\
\hline $18-24$ & $-0.018 *$ & $(0.010)$ & 0.014 & $(0.010)$ \\
\hline $25-34$ & -0.011 & $(0.008)$ & 0.004 & $(0.008)$ \\
\hline $35-44$ & Ref. & & Ref. & \\
\hline $45-54$ & 0.010 & $(0.008)$ & 0.008 & $(0.009)$ \\
\hline $55-64$ & $0.016^{*}$ & $(0.009)$ & -0.013 & $(0.010)$ \\
\hline $65+$ & 0.012 & $(0.009)$ & -0.013 & $(0.011)$ \\
\hline Married/ living with partner & $0.024 * * *$ & $(0.005)$ & 0.007 & $(0.006)$ \\
\hline Children in the household & -0.003 & $(0.006)$ & 0.002 & $(0.006)$ \\
\hline \multicolumn{5}{|l|}{ Education } \\
\hline Primary & $-0.019 * * *$ & $(0.006)$ & $-0.020 * * *$ & $(0.007)$ \\
\hline Secondary & Ref. & & Ref. & \\
\hline Tertiary & $0.037 * * *$ & $(0.006)$ & $0.018 * *$ & $(0.007)$ \\
\hline Wealth index & $0.014 * * *$ & $(0.002)$ & $0.021 * * *$ & $(0.002)$ \\
\hline \multicolumn{5}{|l|}{ Type of residence } \\
\hline Rural & $-0.018 * * *$ & $(0.005)$ & $-0.012 *$ & $(0.006)$ \\
\hline Urban & Ref. & & Ref. & \\
\hline Metropolitan & $-0.030 * * *$ & $(0.008)$ & -0.001 & $(0.008)$ \\
\hline Country-fixed effects & Yes & & Yes & \\
\hline Observations & 29,00 & & 29,00 & \\
\hline Pseudo- $\mathrm{R}^{2}$ & 0.272 & & 0.136 & \\
\hline Prob $>\mathrm{Chi}^{2}$ & 0.000 & & 0.000 & \\
\hline
\end{tabular}

Notes: Robust standard errors in parentheses. ${ }^{* * *} \mathrm{p}<0.01,{ }^{* *} \mathrm{p}<0.05,{ }^{*} \mathrm{p}<0.1$. 
Next, to check whether the relationship between the crisis and different types of proenvironmental behaviour, we estimated the model for different pro-environmental actions. The results are shown in Table 4 (here and in what follows we only report the marginal effects of the variables of interest, i.e., the crisis dummies; complete econometric output is available in the Supplementary Information document). The results suggest that people affected by the crisis are more likely to have undertaken virtually all types of pro-environmental behaviour. In absolute terms, larger associations are observed in the specifications capturing reduced consumption of water, energy, disposable items and transport, which would support the conjecture that people affected by the crisis adopt pro-environmental behaviour to reduce the cost of living. For renewable energy equipment specifications, the effect is small and non-linear (people moderately affected by the crisis are the most likely to install renewable energy equipment), which can be explained by the fact that large crisis-induced income falls prevent people from buying relatively expensive equipment.

Next, to get a better understanding of what type of crisis effects are associated with proenvironmental behaviour, we regressed the two dependent variables on different ways in which the crisis could affect households, ${ }^{10}$ alongside the full set of control variables. The results, reported in Table 5, show that all types of crisis effects except family business closure are positively associated with pro-environmental action. Among other things, this finding supports the way in which the crisis may affect pro-environmental action through both the reduced income and increased time channels: the positive and significant estimates of the reduced/delayed/suspended

\footnotetext{
${ }^{10}$ We consider only the main, non-overlapping effects, as shown in Table 2. Replacing those with the 'all-that-apply' effects does not substantially change the results.
} 
wage and reduced remittances variables speak in favour of the reduced income channel, the reduced working hours in favour of the increased time channel, and the job loss variables support both. The association between the willingness to pay for climate change mitigation and different effects of the crisis is statistically insignificant for all crisis dummies, except the reduced flow of remittances which is negative and significant at $10 \%$. 
Table 4. Effects of the crisis and different types of pro-environmental behaviour, probit average marginal effects

\begin{tabular}{|c|c|c|c|c|c|}
\hline & $\begin{array}{l}\text { Bought an } \\
\text { efficient car }\end{array}$ & $\begin{array}{l}\text { Reduced use } \\
\text { of own car }\end{array}$ & $\begin{array}{l}\text { Chosen pro- } \\
\text { environmental } \\
\text { transport }\end{array}$ & $\begin{array}{c}\text { Reduced } \\
\text { energy } \\
\text { consumption }\end{array}$ & $\begin{array}{c}\text { Reduced } \\
\text { water } \\
\text { consumption } \\
\end{array}$ \\
\hline \multicolumn{6}{|l|}{ Affected by the crisis } \\
\hline Not at all & Ref. & Ref. & Ref. & Ref. & Ref. \\
\hline \multirow[t]{2}{*}{ Just a little } & $0.009^{* *}$ & $0.017 * * *$ & $0.011 * *$ & $0.027 * * *$ & $0.021 * * *$ \\
\hline & $(0.004)$ & $(0.004)$ & $(0.005)$ & & \\
\hline \multirow{2}{*}{ A fair amount } & $0.009 * *$ & $0.019 * * *$ & $0.022 * * *$ & $0.038^{* * *}$ & $0.033 * * *$ \\
\hline & $(0.004)$ & $(0.004)$ & $(0.005)$ & $(0.006)$ & $(0.006)$ \\
\hline \multirow{2}{*}{ A great deal } & $0.009 *$ & $0.031 * * *$ & $0.032 * * *$ & $0.026 * * *$ & $0.031 * * *$ \\
\hline & $(0.005)$ & $(0.006)$ & $(0.006)$ & $(0.007)$ & $(0.007)$ \\
\hline Individual-level controls & Yes & Yes & Yes & Yes & Yes \\
\hline Country-fixed effects & Yes & Yes & Yes & Yes & Yes \\
\hline Observations & 28,360 & 27,841 & 28,485 & 29,004 & 29,004 \\
\hline Pseudo $\mathrm{R}^{2}$ & 0.221 & 0.220 & 0.197 & 0.245 & 0.193 \\
\hline \multirow[t]{2}{*}{ Prob $>\mathrm{Chi}^{2}$} & 0.000 & 0.000 & 0.000 & 0.000 & 0.000 \\
\hline & Avoid flights & $\begin{array}{l}\text { Waste } \\
\text { recycling }\end{array}$ & $\begin{array}{c}\text { Fewer } \\
\text { disposable } \\
\text { items }\end{array}$ & $\begin{array}{l}\text { Buy local } \\
\text { and seasonal } \\
\text { products }\end{array}$ & $\begin{array}{c}\text { Installed } \\
\text { renewable } \\
\text { energy } \\
\text { equipment }\end{array}$ \\
\hline \multicolumn{6}{|l|}{ Affected by the crisis } \\
\hline Not at all & Ref. & Ref. & Ref. & Ref. & Ref. \\
\hline \multirow[t]{2}{*}{ Just a little } & -0.002 & $0.014^{* *}$ & $0.010^{*}$ & $0.010^{* *}$ & $0.004 *$ \\
\hline & $(0.003)$ & $(0.006)$ & $(0.005)$ & $(0.005)$ & $(0.002)$ \\
\hline \multirow[t]{2}{*}{ A fair amount } & -0.004 & $0.020^{* * *}$ & $0.028^{* * *}$ & $0.021^{* * *}$ & 0.003 \\
\hline & $(0.003)$ & $(0.006)$ & $(0.006)$ & $(0.005)$ & $(0.002)$ \\
\hline \multirow[t]{2}{*}{ A great deal } & $0.009^{* *}$ & $0.014 * *$ & $0.021 * * *$ & $0.013^{* *}$ & 0.002 \\
\hline & $(0.003)$ & $(0.007)$ & $(0.007)$ & $(0.006)$ & $(0.003)$ \\
\hline Individual-level controls & Yes & Yes & Yes & Yes & Yes \\
\hline Country-fixed effects & Yes & Yes & Yes & Yes & Yes \\
\hline Observations & 27,565 & 29,004 & 29,004 & 29,004 & 25,599 \\
\hline Pseudo $\mathrm{R}^{2}$ & 0.205 & 0.335 & 0.232 & 0.217 & 0.203 \\
\hline Prob $>\mathrm{Chi}^{2}$ & 0.000 & 0.000 & 0.000 & 0.000 & 0.000 \\
\hline
\end{tabular}

Notes: ${ }^{*} p<0.10,{ }^{* *} p<0.05, * * * p<0.01$. Robust standard errors in parentheses. All regressions include the same control variables as in Table 3. See table S4 of Supplementary Information for complete econometric output. 
Table 5. Different effects of the crisis and pro-environmental behaviour, binary probit average marginal effects

Pro-environmental action $\quad \begin{gathered}\text { Willingness to pay for } \\ \text { climate change mitigation }\end{gathered}$

\begin{tabular}{lrrrr} 
Head of household lost job & $0.030^{* * *}$ & $(0.010)$ & 0.005 & $(0.010)$ \\
Other household member lost job & $0.022^{* *}$ & $(0.010)$ & -0.014 & $(0.011)$ \\
Family business closed & 0.029 & $(0.020)$ & -0.001 & $(0.022)$ \\
Working hours reduced & $0.026^{* *}$ & $(0.013)$ & 0.001 & $(0.014)$ \\
Wages delayed or suspended & $0.032^{* * *}$ & $(0.011)$ & 0.003 & $(0.012)$ \\
Wages reduced & $0.024^{* * *}$ & $(0.007)$ & -0.010 & $(0.008)$ \\
Reduced flow of remittances & $0.039^{* * *}$ & $(0.010)$ & $-0.022^{*}$ & $(0.011)$ \\
& & & Yes \\
Individual-level controls & Yes & Yes \\
Country-fixed effects & Yes & \\
& & 29,004 \\
\hline Observations & 29,004 & 0.135 \\
Pseudo $\mathrm{R}^{2}$ & 0.271 & 0.000 \\
Prob $>$ Chi $^{2}$ & 0.000 & \\
\hline
\end{tabular}

Notes: $* p<0.10, * * p<0.05,{ }^{* * *} p<0.01$. Robust standard errors in parentheses. All regressions include the same control variables as in Table 3. See table S5 of Supplementary Information for complete econometric output.

Next, we turn to heterogeneity analyses. The Life in Transition-2 survey, on which this study is based, was administered in a range of European and Central Asian countries which differ markedly in terms of their economic and social development. This allows us to test whether the link between the crisis and pro-environmentalism is the same across countries with different income levels. Using the World Bank country income classification by GDP per capita for 2010 (when the survey was conducted), we divided the total sample into the sub-samples of 1) low ${ }^{11}$ and lower-middle-income countries; 2) higher-middle-income countries; and 3) high-income countries. The results, reported in Table 6, suggest that people affected by the crisis are more likely to have undertaken at least one pro-environmental action in all country groups. The size of the association is comparable in absolute terms - people affected by the crisis are 2-6 percentage

\footnotetext{
${ }^{11}$ There are only two low-income countries in the sample - Kyrgyzstan and Tajikistan - which is why we merge them with the lower-middle-income country group.
} 
points more likely to have undertaken at least one pro-environmental action. However, the relative contribution of the crisis to pro-environmental action is greater in countries with lower GDP per capita, as the share of respondents having undertaken at least one pro-environmental action in high-income, upper-middle-income and lower-middle/low-income countries is 50, 20 and 11 percent, respectively. This said, some country group differences are observed in the model explaining willingness to pay for climate change mitigation. Specifically, people affected by the crisis in low/lower-middle-income and high-income countries are less likely to sacrifice income to combat climate change, while the association between crisis effects and willingness to pay is insignificant in the upper-middle-income country group. 
Table 6. Effects of the crisis and pro-environmental behaviour, by country income level, binary probit average marginal effects

\begin{tabular}{|c|c|c|c|}
\hline & & Pro-environmental action & $\begin{array}{l}\text { Willingness to pay for } \\
\text { climate change mitigation }\end{array}$ \\
\hline \multirow{3}{*}{$\begin{array}{l}\text { A. Low and lower-middle- } \\
\text { income countries (10) }\end{array}$} & Affected by the crisis & & \\
\hline & Not at all & Ref. & Ref. \\
\hline & Just a little & $0.030 * * * \quad(0.012)$ & $0.020 \quad(0.017)$ \\
\hline \multirow{7}{*}{$\begin{array}{l}\text { (Albania, Armenia, Georgia, } \\
\text { Kosovo, Kyrgyzstan, } \\
\text { Moldova, Mongolia, Ukraine, } \\
\text { Uzbekistan, Tajikistan) }\end{array}$} & A fair amount & $0.035 * * * \quad(0.011)$ & $-0.026 \quad(0.016)$ \\
\hline & A great deal & $0.041 * * * \quad(0.013)$ & $-0.054 * * * \quad(0.017)$ \\
\hline & Individual-level controls & Yes & Yes \\
\hline & Country-fixed effects & Yes & Yes \\
\hline & Observations & 7,250 & 7,250 \\
\hline & Pseudo $\mathrm{R}^{2}$ & 0.163 & 0.116 \\
\hline & Prob $>\mathrm{Chi}^{2}$ & 0.000 & 0.000 \\
\hline \multirow{3}{*}{$\begin{array}{l}\text { B: Upper-middle-income } \\
\text { countries (13) }\end{array}$} & Affected by the crisis & & \\
\hline & Not at all & Ref. & Ref. \\
\hline & Just a little & $0.023 *(0.011)$ & $0.016 \quad(0.014)$ \\
\hline \multirow{7}{*}{$\begin{array}{l}\text { (Azerbaijan, Belarus, Bosnia- } \\
\text { Herzegovina, Bulgaria, } \\
\text { Kazakhstan, Latvia, } \\
\text { Lithuania, FYR Macedonia, } \\
\text { Romania, Russia, Serbia, } \\
\text { Turkey, Montenegro) }\end{array}$} & A fair amount & $0.032 * * * \quad(0.011)$ & $0.003 \quad(0.012)$ \\
\hline & A great deal & $0.028 * * \quad(0.012)$ & $-0.015 \quad(0.013)$ \\
\hline & Individual-level controls & Yes & Yes \\
\hline & Country-fixed effects & Yes & Yes \\
\hline & Observations & 10,753 & 10,753 \\
\hline & Pseudo $\mathrm{R}^{2}$ & 0.182 & 0.119 \\
\hline & Prob $>\mathrm{Chi}^{2}$ & 0.000 & 0.000 \\
\hline C: High-income countries & Affected by the crisis & & \\
\hline (12) & Not at all & Ref. & Ref. \\
\hline \multirow{8}{*}{$\begin{array}{l}\text { (Croatia, Czech Republic, } \\
\text { Estonia, France, Germany, } \\
\text { Hungary, Italy, Poland, } \\
\text { Slovakia, Slovenia, Sweden, } \\
\text { United Kingdom) }\end{array}$} & Just a little & $0.033^{* * *} \quad(0.011)$ & $0.005 \quad(0.011)$ \\
\hline & A fair amount & $0.047 * * * \quad(0.012)$ & $-0.023 * \quad(0.012)$ \\
\hline & A great deal & $0.047 * * * \quad(0.016)$ & $-0.030 * * \quad(0.015)$ \\
\hline & Individual-level controls & Yes & Yes \\
\hline & Country-fixed effects & Yes & Yes \\
\hline & Observations & 11,001 & 11,001 \\
\hline & Pseudo $\mathrm{R}^{2}$ & 0.192 & 0.159 \\
\hline & Prob $>\mathrm{Chi}^{2}$ & 0.000 & 0.000 \\
\hline
\end{tabular}

Notes: $* p<0.10, * * p<0.05, * * * p<0.01$. Robust standard errors in parentheses. All regressions include the same controls as in Table 3. See Table S6 of Supplementary Information for complete econometric output.

Finally, we checked whether particular socio-demographic groups - women and men, younger

(age $<45)$ and older (age $\geq 45)$ respondents, less educated (primary and secondary education) and more educated (tertiary education) respondents, as well as respondents from households with relatively low and relatively high wealth (based on the within-country median split of the wealth index) - are more likely to drive the relationship between the effects of the crisis and pro- 
environmental behaviour. The results, reported in Table 7, suggest that the positive association between being affected by the crisis and having undertaken pro-environmental action differs little across the socio-demographic groups. In the model explaining willingness to pay for climate change mitigation, the negative and significant coefficient of the crisis variable is also obtained for women and men, younger and older respondents, and households with higher and lower wealth. The only difference arises across education groups: people affected by the crisis and educated to the primary and secondary level are less willing to pay for climate change mitigation, while the crisis coefficients are statistically insignificant in the sample of the tertiary educated. 
Table 7. Effects of the crisis and pro-environmental behaviour, by socio-demographic group, probit average marginal effects

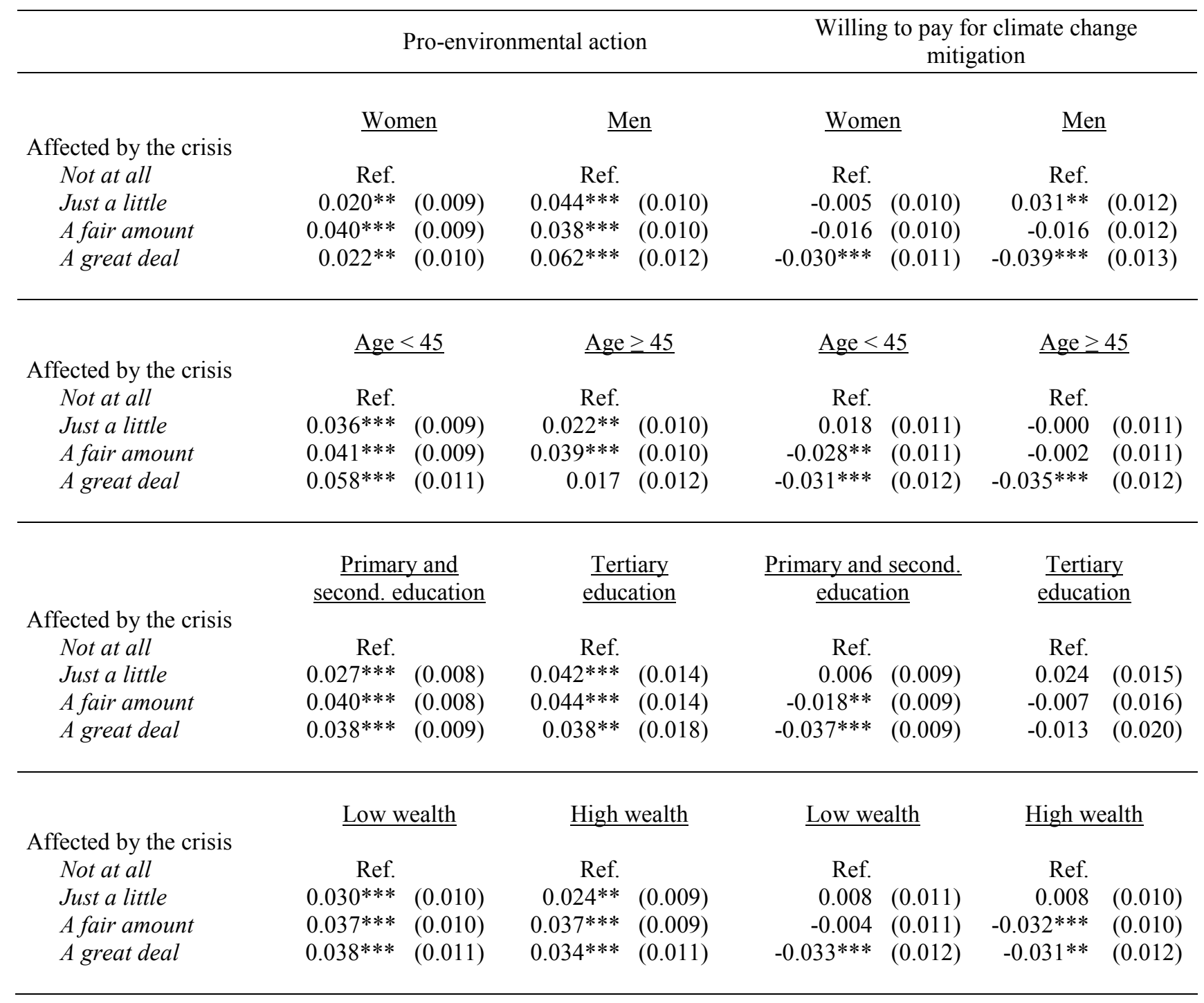

Notes: $* p<0.10, * * p<0.05, * * * p<0.01$. Robust standard errors in parentheses. The table reports the results of the crisis dummies for 16 regressions estimating the action and willingness to pay models for different sociodemographic groups; all regressions include the same controls as in Table 3. See Table S7a and S7b of Supplementary Information for complete econometric output. 


\section{DISCUSSION AND CONCLUSION}

This paper set out to determine how adverse welfare shocks affect people's pro-environmental behavior. Drawing on a large representative survey, conducted in 35 European and Central Asian countries, the study analysed the household-level relationship between being a victim of the 200809 global economic crisis, on the one hand, and pro-environmental action and willingness to pay for climate change mitigation, on the other. The results revealed that people affected by the crisis are more likely to act in environmentally-friendly way, but less likely to be willing to pay for climate change mitigation. Most types of crisis effects (e.g., job loss, salary reduction, reduced migrant remittances) are positively associated pro-environmental action, and most types of proenvironmental action (e.g., reduced use of transport, reduced water and energy consumption, waste recycling) are positively associated with being a crisis victim. The positive association between the crisis and pro-environmental action is observed in countries with different levels of GDP per capita and across different socio-economic groups. The negative association with the willingness to pay for climate change mitigation is driven by relative poor and relatively rich countries, as well as respondents with lower levels of education.

What could explain these findings? The greater likelihood of pro-environmental action among people who experienced crisis-related salary reductions or job losses indicates that tightened financial and relaxed time constraints matter. For example, people who have suddenly lost their jobs need to reduce energy consumption to save money but may also choose to start recycling waste or shopping for seasonal and local products because they have more time to do so. This links to the literature showing that poorer people are more likely to adopt pro-environmental behaviour - by necessity rather than choice (Bruderer Enzler and Diekmann, 2015; Longhi, 2013) 
- and that people undertake pro-environmental activities if they have time to do so and the opportunity costs of time are low (see e.g. Matsumoto, 2014). The lower willingness to pay for climate change mitigation, especially among people with lower levels of education, probably reflects a change in people's life priorities towards more basic needs after the crisis hit. A finding that people affected by the crisis are less willing to pay for climate change mitigation also in relatively low-income and high-income countries (and not middle-income countries) appears more puzzling and requires further investigation; we leave it for future research.

Concerning the policy implications of this study, it is clear that encouraging economic crises, as well as any other policy that would result in income or job loss, would not find much support among any stakeholder group (general public, environmentalists, policymakers), even if such policies may lead to environmental gains. However, an important lesson from our study is that time constraints matter for pro-environmental behaviour. From this perspective, initiatives to shorten time that people spend at work - for example by reducing the working day from eight to six hours (and keeping workers' salary at the same level) - may have positive effects not only on workers' productivity and subjective well-being (see e.g. Kozicka (2015) for Swedish experience) but also encourage more pro-environmental action. Similarly, initiatives to limit people's access to corporate email outside of working hours (Koch, 2014; Schofield, 2016) may free up the necessary time for undertaking pro-environmental activities. Another way to make people spend more time at home is to apply higher taxes on income generated in overtime work. Theoretically, such policy should lower the opportunity costs of undertaking pro-environmental action and lead to greater levels of it; it is, however, unclear whether such policy will resonate well with both employees and employers. 
A broader message of this study to policymakers would be that economic crises have a range of effects - direct and indirect, expected and unexpected - on various domains of human life. While, unsurprisingly, the recent global economic crisis was found to make people's lives worse - it is, for example, likely to have contributed to lower subjective well-being (Welsch and Kühling, 2016), mental health problems (Deaton, 2012; Falconier, 2010; Katikireddi et al., 2012), suicides (Barr et al., 2012), and public sector corruption (Ivlevs and Hinks, 2015) - there are also indications that not all crisis effects are harmful. For example, crises are generally accompanied by fewer traffic-related fatalities, fewer cardiovascular and respiratory problems, and lower levels of infant mortality, because during crises people drive and pollute less (Burgard and Kalousova, 2015). This paper suggests that the recent crisis may have prompted people to undertake proenvironmental actions.

Our work is not without limitations. First, countries included in our analysis are, for the most part, middle-income and post-socialist. Although we able to perform some country heterogeneity analysis, caution should be applied when generalising the results of this study to countries with relatively high or relatively low average income levels, as well as to other parts of the world. Second, the results of this study should be interpreted as conditional correlations rather than causal effects. While one can convincingly rule out reverse causality - it is highly unlikely that global crises selectively hit people with a more pro-environmental stance, we cannot exclude an estimation bias from not accounting for factors which simultaneously affect one's likelihood of becoming a crisis victim and acting pro-environmentally. If such factors are time-invariant (e.g., personality traits), the use of longitudinal data, where the same respondents are observed over 
time, is one way to control for unobserved respondent heterogeneity and to move closer to causal evidence. This is an important direction for future research; one has to bear in mind, however, that obtaining nationally representative longitudinal data for one or more countries requires substantial resources and may be a challenge in itself. ${ }^{12}$

In conclusion, using data from a large, nationally representative survey carried out in 35 European and Central Asian countries, this study has revealed a robust positive association between being adversely affected by the global economic crisis and undertaking environmental action. This relationship is observed in countries at different stages of economic development and across different socio-demographic groups. At the same time, people affected by the crisis are less likely to report willingness to pay for climate change mitigation. These results highlight the importance of financial and time constraints for pro-environmental behaviour, and suggest that sudden welfare losses experienced by people during economic crises may lead to environmental gains.

\footnotetext{
12 The existing longitudinal datasets may not always contain the necessary variables. For example, the European Union Statistics on Income and Living Conditions survey (EU-SILC) contains questions on income and labour markets (which could capture the effects of the crisis), but not environmental concern and behaviours.
} 


\section{Appendix}

Summary statistics of the variables included in the analysis

\begin{tabular}{|c|c|c|c|c|c|}
\hline Variable & $\mathrm{N}$ & Mean & $\begin{array}{l}\text { Std. } \\
\text { Dev. }\end{array}$ & Min & Max \\
\hline Undertaken at least one pro-environmental action & 37420 & 0.283 & 0.450 & 0 & 1 \\
\hline Willing to pay to combat climate change & 37420 & 0.316 & 0.465 & 0 & 1 \\
\hline Concerned about climate change & 37420 & 3.303 & 1.186 & 1 & 5 \\
\hline Informed about climate change & 34894 & 9.180 & 2.921 & 4 & 16 \\
\hline Pro-environmental beliefs & 30215 & 7.093 & 1.498 & 2 & 10 \\
\hline \multicolumn{6}{|l|}{ Affected by the crisis } \\
\hline Not at all & 37420 & 0.271 & 0.445 & 0 & 1 \\
\hline Just a little & 37420 & 0.232 & 0.422 & 0 & 1 \\
\hline A fair amount & 37420 & 0.270 & 0.444 & 0 & 1 \\
\hline A great deal & 37420 & 0.172 & 0.378 & 0 & 1 \\
\hline No answer & 37420 & 0.055 & 0.227 & 0 & 1 \\
\hline Female & 37420 & 0.602 & 0.489 & 0 & 1 \\
\hline Married/partner & 37420 & 0.615 & 0.487 & 0 & 1 \\
\hline Children in the household & 37420 & 0.369 & 0.483 & 0 & 1 \\
\hline \multicolumn{6}{|l|}{ Age group } \\
\hline $18-24$ & 37420 & 0.118 & 0.322 & 0 & 1 \\
\hline $25-34$ & 37420 & 0.194 & 0.396 & 0 & 1 \\
\hline $35-44$ & 37420 & 0.188 & 0.391 & 0 & 1 \\
\hline $45-54$ & 37420 & 0.176 & 0.381 & 0 & 1 \\
\hline $55-64$ & 37420 & 0.155 & 0.362 & 0 & 1 \\
\hline $65+$ & 37420 & 0.169 & 0.374 & 0 & 1 \\
\hline \multicolumn{6}{|l|}{ Education } \\
\hline Primary & 37420 & 0.303 & 0.460 & 0 & 1 \\
\hline Secondary & 37420 & 0.492 & 0.500 & 0 & 1 \\
\hline Tertiary & 37420 & 0.205 & 0.404 & 0 & 1 \\
\hline Wealth index & 37420 & 0.489 & 1.837 & -2.320 & 3.836 \\
\hline \multicolumn{6}{|l|}{ Type of residence } \\
\hline Rural & 37420 & 0.397 & 0.489 & 0 & 1 \\
\hline Urban & 37420 & 0.472 & 0.499 & 0 & 1 \\
\hline Metropolitan & 37420 & 0.132 & 0.338 & 0 & 1 \\
\hline
\end{tabular}




\section{REFERENCES}

Aguiar, M., E. Hurst and L. Karabarbounis, 2013, Time Use During the Great Recession, The American Economic Review 103, 1664-1696.

Akter, S. and J. Bennett, 2011, Household perceptions of climate change and preferences for mitigation action: the case of the Carbon Pollution Reduction Scheme in Australia, Climatic Change 109, 417-436.

Ambrosius, J.D. and J.I. Gilderbloom, 2015, Who's greener? Comparing urban and suburban residents' environmental behaviour and concern, Local Environment 20(7), 836-14.

Ando, A. W. and A. Y. Gosselin, 2005, Recycling in multifamily dwellings: Does convenience matter? Economic Inquiry 43, 426-438.

Barr, B., D. Taylor-Robinson, A. Scott-Samuel, M. McKee and D. Stuckler, 2012, Suicides associated with the 2008-10 economic recession in England: time trend analysis, BMJ: British Medical Journal 345, 13-13.

Bruderer Enzler, H. and A. Diekmann, 2015, Environmental Impact and Pro-Environmental Behavior: Correlations to Income and Environmental Concern. ETH Zurich Sociology Working Paper 9-2015.

Burgard, S. and L. Kalousova, 2015, Effects of the Great Recession: Health and Well-Being. Annual Review of Sociology 41, 181-201.

Çarkoğlu, A. and Ç Kentmen-Çin, 2015, Economic development, environmental justice, and proenvironmental behavior, Environmental Politics 24, 575-597.

Carlsson, F., M. Kataria, A. Krupnick, E. Lampi, Å Löfgren, P. Qin, S. Chung, T. Sterner, , 2012, Paying for Mitigation: A Multiple Country Study, Land Economics 88, 326-340. 
Clark, C., M. Kotchen and M. Moore, 2003, Internal and external influences on pro-environmental behavior: Participation in a green electricity program, Journal of Environmental Psychology 23, 237-246.

Deaton, A., 2012, The financial crisis and the well-being of Americans, Oxford Economic Papers 64, 1-26.

Diekmann, A. and A. Franzen, 1999, The Wealth of Nations and Environmental Concern, Environment and Behavior 31, 540-549.

Dienes, C., 2015, Actions and intentions to pay for climate change mitigation: Environmental concern and the role of economic factors, Ecological Economics 109, 122-129.

Dorsch, M.T., 2014, Economic Development and Determinants of Environmental Concern, Social Science Quarterly 95, 960-977.

Dunlap, R.E. and A.G. Mertig, 1997, Global Environmental Concern: An Anomaly for Postmaterialism, Social Science Quarterly 78, 24-29.

Dunlap, R.E. and A.G. Mertig, 1995, Global Concern for the Environment: Is Affluence a Prerequisite? Journal of Social Issues 51, 121-137.

Fairbrother, M., 2013, Rich People, Poor People, and Environmental Concern: Evidence across Nations and Time, European Sociological Review 29, 910-922.

Falconier, M.K., 2010, Female Anxiety and Male Depression: Links Between Economic Strain and Psychological Aggression in Argentinean Couples, Family Relations 59, 424-438.

Franzen, A. and R. Meyer, 2010, Environmental Attitudes in Cross-National Perspective: A Multilevel Analysis of the ISSP 1993 and 2000, European Sociological Review 26, 219234. 
Franzen, A. and D. Vogl, 2013, Two decades of measuring environmental attitudes: A comparative analysis of 33 countries. Global Environmental Change, 23, 1001-1008.

Halvorsen, B., 2008, Effects of norms and opportunity cost of time on household recycling, Land Economics 84, 501-516.

Inglehart, R., 1995, Public Support for Environmental Protection: Objective Problems and Subjective Values in 43 Societies, PS: Political Science and Politics 28, 57-72.

Inglehart, R., 1997, Modernization and Postmodernization: Cultural, Economic, and Political Change in 43 Societies. Princeton University Press, Chichester; Princeton, N.J.

Israel, D. and A. Levinson, 2004, Willingness to Pay for Environmental Quality: Testable Empirical Implications of the Growth and Environment Literature, Contributions in Economic Analysis \& Policy 3.

Ivlevs, A. and T. Hinks, 2015, Global economic crisis and corruption, Public Choice 162, 425445.

Jacobsen, J.B. and N. Hanley, 2009, Are There Income Effects on Global Willingness to Pay for Biodiversity Conservation? Environmental and Resource Economics 43, 137-160.

Jakus, P. M., K. H. Tiller and W. M. Park, 1996, Generation of recyclables by rural households, Journal of Agricultural and Resource Economics 21(1), 96-108.

Katikireddi, S., C. Niedzwiedz and F. Popham, 2012, Trends in population mental health before and after the 2008 recession: a repeat cross-sectional analysis of the 1991-2010 Health Surveys of England, BMJ OPEN 2, e001790.

Kellstedt, P.M., S. Zahran and A. Vedlitz, 2008, Personal Efficacy, the Information Environment, and Attitudes Toward Global Warming and Climate Change in the United States, Risk Analysis 28, 113-126. 
Koch, M., 2014, Banning e-mail after work, Deutsche Welle, published 20 February 2014, available online at: http://p.dw.com/p/1BCLD

Kozicka, P., 2015, 6-hour workday catching on in Sweden; could it work in Canada? Global News, published 1 October 2015, available online at: http://globalnews.ca/news/2252448/6-hour-workday-catching-on-in-sweden-could-itwork-in-canada/

Liebe, U., P. Preisendörfer and J. Meyerhoff, 2011, To Pay or Not to Pay: Competing Theories to Explain Individuals' Willingness to Pay for Public Environmental Goods, Environment and Behavior 43, 106-130.

Longhi, S., 2013, Individual Pro-environmental Behaviour in the Household Context. ISER Working Paper 2013-21.

Matsumoto, S., 2014, The Opportunity Cost of Pro-Environmental Activities: Spending Time to Promote the Environment, Journal of Family and Economic Issues, 35, 119-130.

Meyer, A., 2015, Does education increase pro-environmental behavior? Evidence from Europe, Ecological Economics, vol. 116, pp. 108-121.

Roco, L., A. Engler, B.E. Bravo-Ureta and R. Jara-Rojas, 2015, Farmers' perception of climate change in mediterranean Chile, Regional Environmental Change 15, 867-879.

Schofield, H., 2016, The plan to ban work emails out of hour, BBC News, published 11 May 2016, available online at http://www.bbc.co.uk/news/magazine-36249647.

Scruggs, L. and S. Benegal, 2012, Declining public concern about climate change: Can we blame the great recession? Global Environmental Change, 22, 505-515.

Steves, F., 2011, Life in transition: After the crisis. London: European Bank for Reconstruction and Development \& World Bank. 
Van Prooijen, A. and P. Sparks, 2014, Attenuating Initial Beliefs: Increasing the Acceptance of Anthropogenic Climate Change Information by Reflecting on Values: Attenuating Initial Beliefs, Risk Analysis 34, 929-936.

Wang, Z., X. Zhang, B. Zhang and J. Yin, 2011, Willingness and behavior towards e-waste recycling for residents in Beijing city, China, Journal of Cleaner Production 19, 977-984.

Welsch, H. and J. Kühling, 2016, How has the crisis of 2008-09 affected subjective well-being? Evidence from 25 OECD countries, Bulletin of Economic Research, 68, 34-54.

Whitmarsh, L., 2011, Scepticism and uncertainty about climate change: Dimensions, determinants and change over time, Global Environmental Change 21, 690-700.

Wicker, P. and S. Becken, 2013, Conscientious vs. ambivalent consumers: Do concerns about energy availability and climate change influence consumer behaviour? Ecological Economics 88, 41-48.

Wong, T.K. and P. Wan, 2011, Perceptions and determinants of environmental concern: the case of Hong Kong and its implications for sustainable development, Sustainable Development $19,235-249$. 